\title{
A Comparative Study on Microstructure Properties of AZ91 Magnesium Alloy with Silicon Addition Using Ceramic Mold
}

\author{
H.A. GÖREN ${ }^{a, *}$, M. ÜNAL ${ }^{b}$ AND E. KOÇ ${ }^{c}$ \\ ${ }^{a}$ Sinop University, Mechatronics Program, Sinop, Turkey \\ ${ }^{b}$ Karabuk University, Department of Manufacturing Engineering, Karabuk, Turkey \\ ${ }^{c}$ Karabuk University, Metallurgical Materials Engineering Department, Karabuk, Turkey
}

\begin{abstract}
In this study, comparatively microstructure and hardness properties of AZ91 alloy with the addition of $1.95 \mathrm{wt} \%$ silicon were investigated by using ceramic mold. For this purpose, the alloys were provided to solidfy in different rates due to using that mold. Alloys cast into this mold showed rapid cooling behavior due to copper in the base, while cooling rate decreased on the top zone. The results showed that $\alpha+\mathrm{Mg}$ main matrix phase is present in AZ91 structure, $\mathrm{Mg}-\mathrm{Al}$ eutectic and $\mathrm{Mg}_{17} \mathrm{Al}_{12}$ intermetallic phases extending along grain boundaries were observed in the main matrix as well. As the cooling rate increases, the grain boundaries of $\mathrm{Mg}_{17} \mathrm{Al}_{12}$ intermetallic phases were increased. The $\mathrm{Mg}_{17} \mathrm{Al}_{12}$ phase at grain boundaries was partially fragmented with the addition of Si. Coarsen $\mathrm{Mg}_{2} \mathrm{Si}$ phases were also formed with the addition of $1.95 \mathrm{wt} \%$ silicon. The hardness values were increased with the increasing of cooling rate and the addition of silicon.
\end{abstract}

DOI: 10.12693/APhysPolA.135.884

PACS/topics: AZ91, ceramic mold, microstructure, hardness

\section{Introduction}

Magnesium $(\mathrm{Mg})$ alloys are used as the lightest metal engineering material. They are used in many areas such as microelectronics, aerospace, automobile industry for their low density. $\mathrm{Mg}$ alloys unite features such as strength, durability, good machinability and good castability under controlled atmosphere $[1,2]$. Besides, $\mathrm{Mg}$ is $78 \%$ lighter than iron and steel, $36 \%$ lighter than aluminum in weight [3]. Among Mg alloys, AZ91 (Mg-9Al1Zn) $\mathrm{Mg}$ alloy is remarkable with its good combination provided in terms of its castability, good mechanical characteristics [4]. Solubility of silicon ( $\mathrm{Si}$ ) in $\mathrm{Mg}$ is low. With the addition of $\mathrm{Si}$ to $\mathrm{Mg}, \mathrm{Mg}_{2} \mathrm{Si}$ intermetallic occurs. While grain structure of the alloy became thinner with the increase in cooling rate of AZ91 Mg alloy, amount of $(\beta)$ phase decreased and network shape became corrupted [5]. In this study, AZ91 and AZ91 1.95 wt\% Si added Mg alloys were produced at different cooling rates. The aim of this study is to compare hardness characteristics and microstructure between these two alloys.

\section{Experimental procedure}

Melting alloys waere done in 3-kg capacity steel crucible. Furnace and metal temperature was determined as $750^{\circ} \mathrm{C}$ as considering real casting conditions. The furnace was hold for about $15 \mathrm{~min}$ at the desired temperature. During casting, $\mathrm{SF}_{6}$ protective gas was given to liquid

*corresponding author; e-mail: agoren@sinop.edu.tr

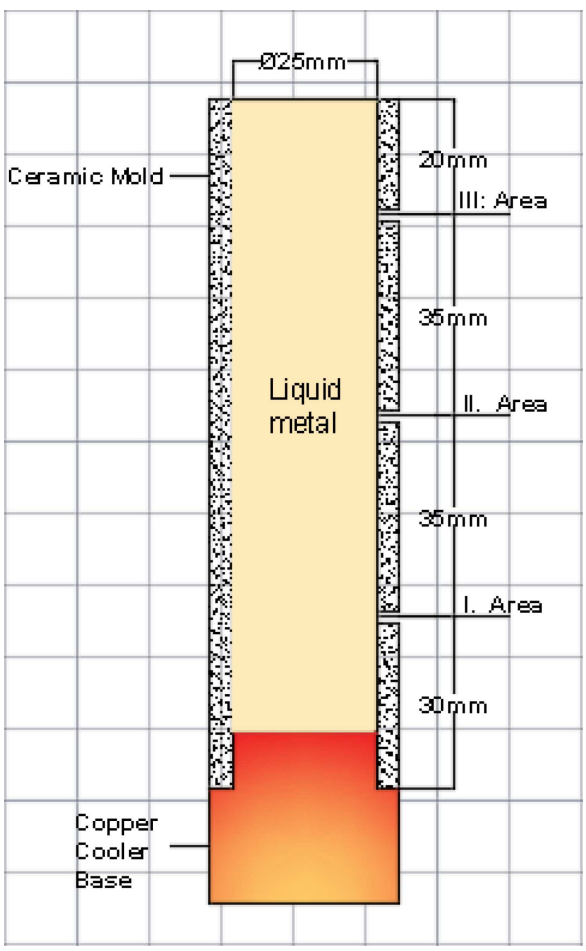

Fig. 1. Copper cooler ceramic mold section used in casting process.

Chemical composition of alloys.

TABLE I

\begin{tabular}{c|c|c|c|c|c}
\hline \hline Sample & $\mathrm{Al}$ & $\mathrm{Zn}$ & $\mathrm{Mn}$ & $\mathrm{Si}$ & $\mathrm{Mg}$ \\
\hline AZ91 & 9.37 & 0.83 & 0.20 & 0.05 & bal. \\
AZ91+1.95 wt\% Si & 9.30 & 0.75 & 0.20 & 1.95 & bal.
\end{tabular}


metal and molds [5]. In addition to $\mathrm{Mg}, \mathrm{Al}$ and $\mathrm{Zn}$ of 99.9\% purity, Al-Si master alloy wys used in preparation of AZ91 Mg alloy. Casting of experiment samples was conducted after secondary melting of prepared preliminary alloys. In tentative studies, AZ91 alloy was added with 1.95 wt\% non-surface-active silicon addition as alloy element. AZ91 alloy and AZ91 alloy with Si addition of $1.95 \mathrm{wt} \%$ were compared. Chemical composition of the alloys used in experiments can be seen in Table I.

In experimental studies, round conical ceramic mold in $\varnothing 25 \times 120 \mathrm{~mm}$ dimensions was used. Bottom of mold was plugged with cooling copper plug. In Fig. 1, ceramic mold used in experimental studies are shown. 1st area which is the closest to copper cooler is the place cooling fastest, 2nd area cools slower, 3rd area cools the slowest. Solidification rates, hardness and microstructure evaluations were conducted from equally spaced 3 different areas.
In hardness tests, pyramid-tipped HMV Shimadzu model digital hardness tester was used. Hardness measurement was taken from 5 different points on the sample surface, and the mean of these measurements were taken. For hardness and microstructure tests, metallographic experiments were carried out.

\section{Results and discussion}

\subsection{Solidification and microstructure}

In experimental studies, microstructure samples were obtained by casting AZ91, AZ91+1.95 wt\% Si alloys into the ceramic plate respectively. Microstructure samples were taken from 3 different areas with various solidification rates. SEM and EDS images of the alloys depending on the cooling rate are shown in Figs. 2-4.

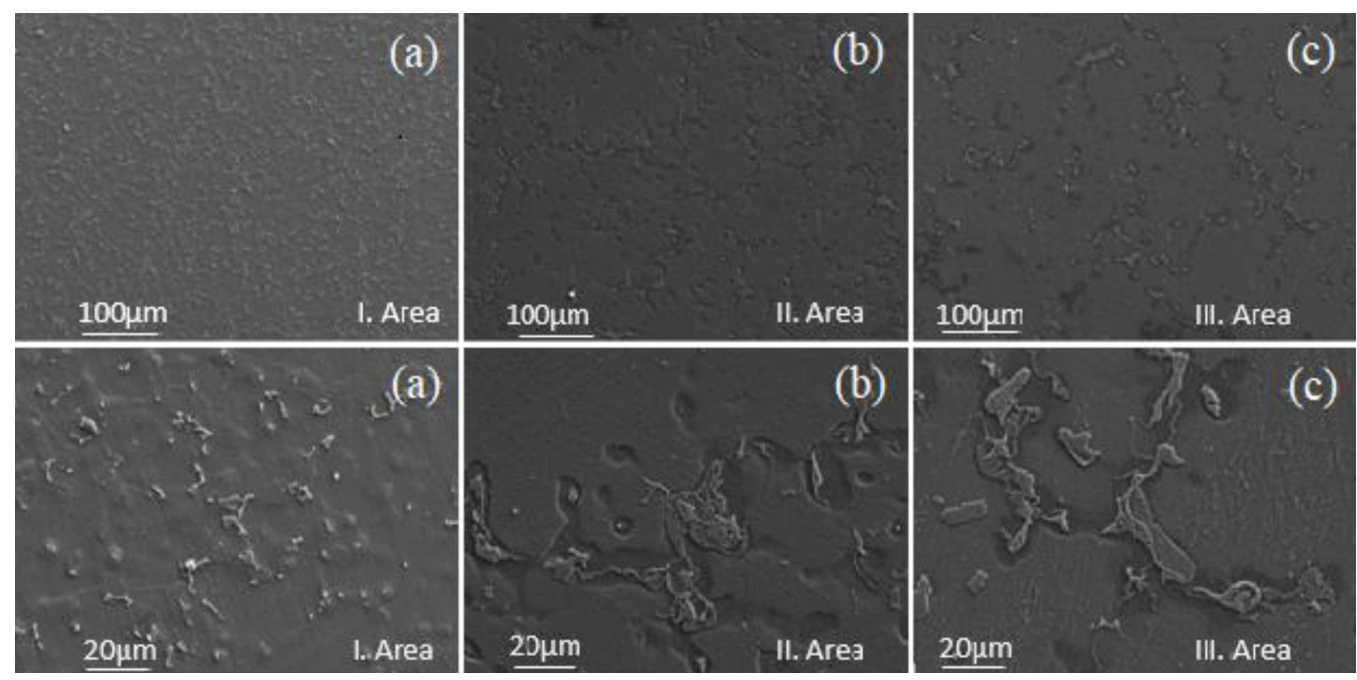

Fig. 2. SEM images of AZ91 alloy depending on the cooling rates (a) I. area, (b) II. area, (c) III. area. Lower row magnification $5 \times$.
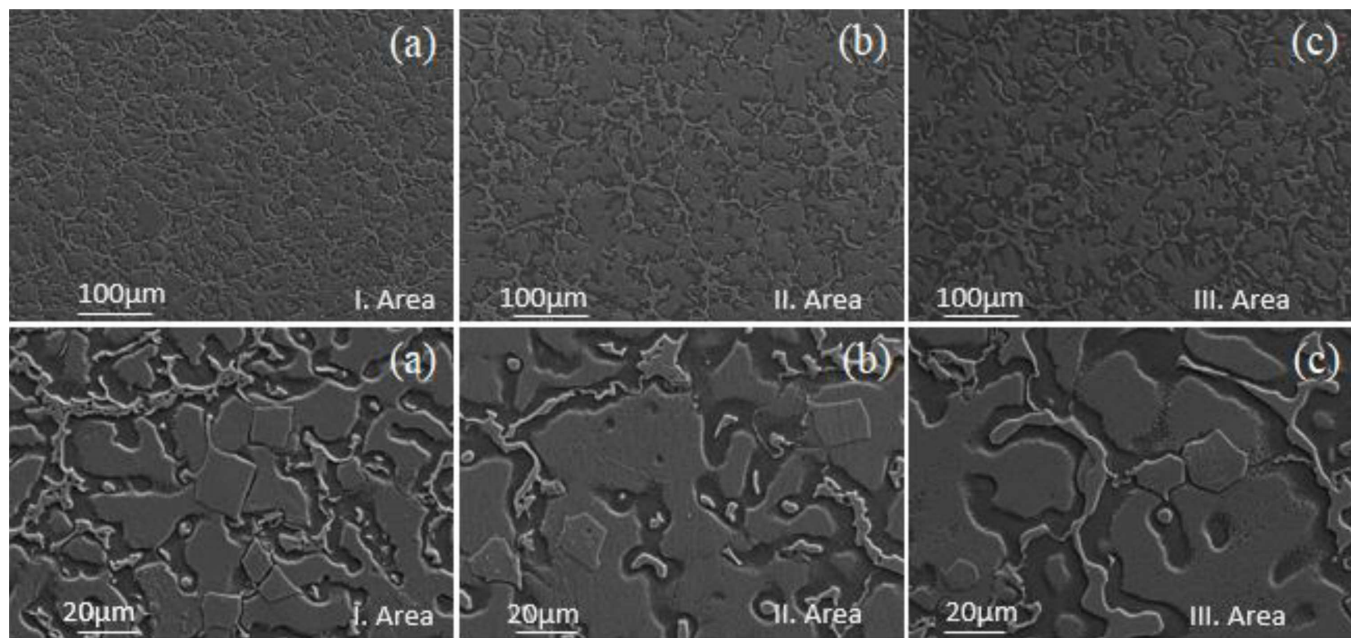

Fig. 3. SEM images of AZ91+1.95 wt\% Si alloy depending on the cooling rates (a) I. area, (b) II. area, (c) III. area. Lower row magnification $5 \times$. 

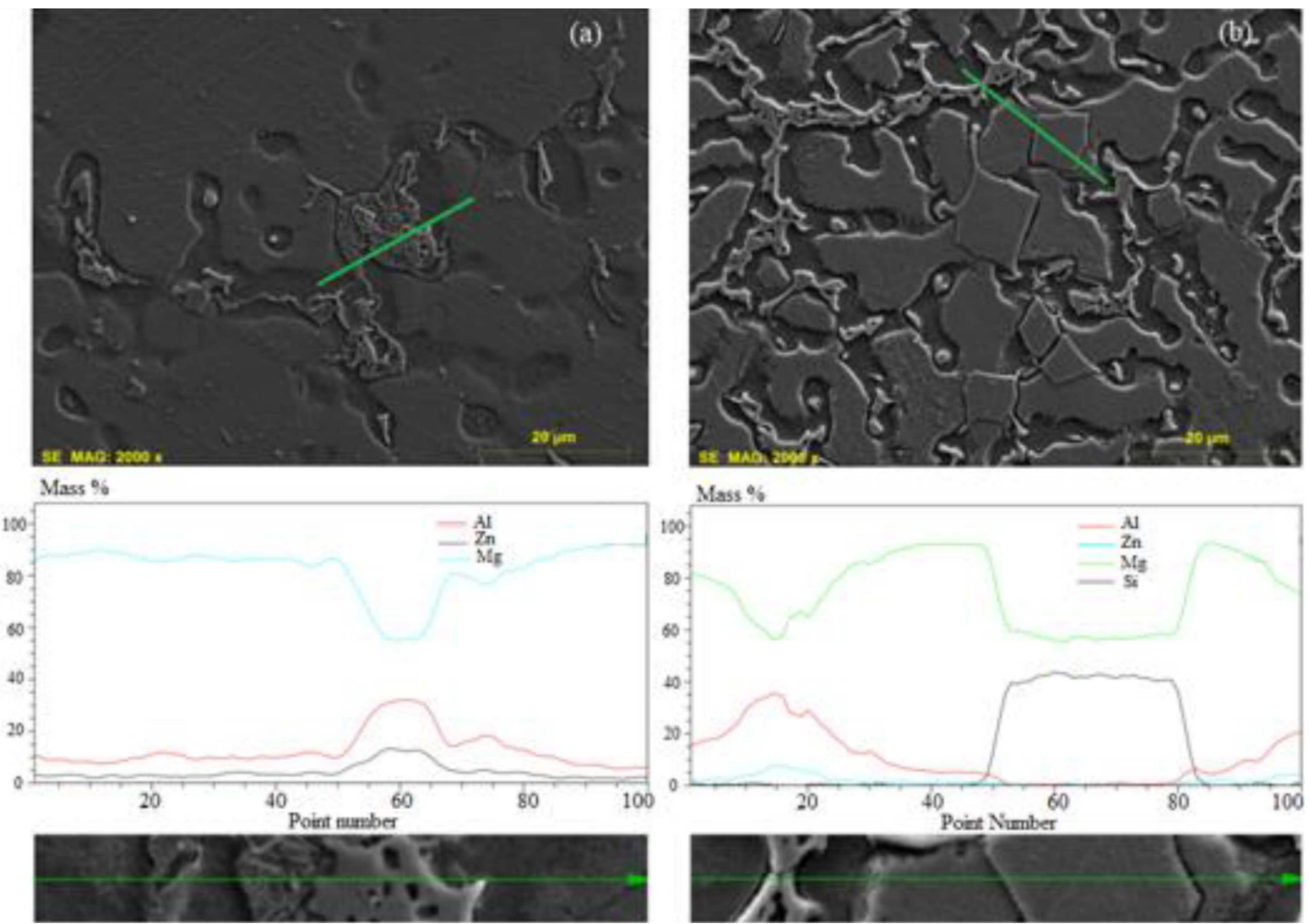

Fig. 4. EDS images of (a) AZ91 and (b) AZ91+1.95 wt\% Si alloys.

In microstructure of AZ91 alloy, $\alpha+\mathrm{Mg}$ main matrix phase, $\mathrm{Mg}-\mathrm{Al}$ eutectic and $(\beta)$ intermetallic are found. Analysing microstructure images, it can be seen that grain size decreases depending of cooling rate and $(\beta)$ intermetallic phase increases in grain limits. With the addition of $\mathrm{Si}, \mathrm{Mg}_{2} \mathrm{Si}$ phase occurred and $(\beta)$ phase was crashed. This situation was previously reported in the literature [5].

\subsection{Hardness}

In this study, hardness of alloys was measured with Vickers hardness measuring method from 3 different areas. Depending on cooling rates in Fig. 5, changes in hardness of AZ91 and AZ91+1.95 wt\% Si Mg alloys were given. As cooling rate increased, hardness also increased. Hardness values in AZ91 alloy were observed respectively as $57.43 \mathrm{HV}$ for the 1st area, 56.76 HV for the 2nd area and $53.50 \mathrm{HV}$ for the 3rd area, and the fasted cooling area was found $1.18 \%$ harder than the 2nd area and $7.34 \%$ harder than the 3rd area. In AZ91+1.95 wt\% Si alloy; the 1st area is $77 \mathrm{HV}$, the 2nd area is $74.10 \mathrm{HV}$ and the 3rd area is $70.60 \mathrm{HV}$, and the 1st area is $4.05 \%$ harder than the 2nd area and $9.06 \%$ harder than the 3rd area. Comparing the same areas of AZ91 and AZ91 $1.95 \mathrm{wt} \%$ $\mathrm{Si}$ alloys, hardness increase in $\mathrm{Si}$ added alloy increased by $34.07 \%$ in the 1 st area, $30.19 \%$ in the 2 nd area and $31.19 \%$ in the 3 rd area.

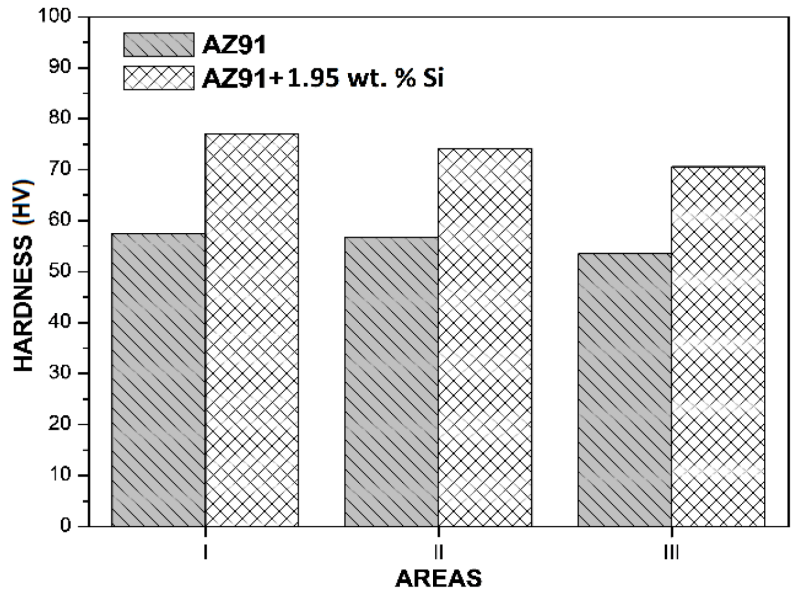

Fig. 5. Hardness changes depending on the cooling rate of the alloys.

\section{Conclusion}

Analysing microstructure of AZ91, it was observed that $\alpha$-Mg main matrix and $(\beta)$ intermetallic phase existed along with grain limits. With the $\mathrm{Si}$ addition, $\mathrm{Mg}_{2} \mathrm{Si}$ intermetallic phase was formed. $\mathrm{Mg}_{2} \mathrm{Si}$ phase crashed $(\beta)$ intermetallic phase. Hardness was increased with $1.95 \mathrm{wt} \% \mathrm{Si}$ addition. In addition, hardness also increased with an increase in cooling rate. 


\section{References}

[1] B.L. Mordike, T. Ebert, Mater. Sci. Eng. 302, 37 (2001).

[2] Magnesium Technology, Eds. M.V. Manuel, A. Singh, M. Alderman, N.R. Neelameggham, Wiley Publishing, 2015.
[3] L. Gaines, R. Cuenca, F. Stodolsky, S. Wu, Potential Automotive Uses of Wrought Magnesium Alloys, Auto. Tech. Development, Detroit, Michigan 1996, p. 1.

[4] I.J. Polmear, Mater. Sci. Technol. 10, 1 (1994).

[5] M. Ünal, H. A. Gören, E. Koc, Y. Türen, H. Ahlatci, Y. Sun, Int. Jour. Mech. Pro. Eng., 5, 25 (2017). 